\title{
Hydrodynamic Modelling of Tidally-Influenced Fluvial Zone, a study case of Palembang, Indonesia
}

\author{
Alamsyah Kurniawan ${ }^{1 *}$, Andi Egon 2,3 , Karina Aprilia Sujatmiko²,4, Ardi Iman Malakani² \\ ${ }^{1}$ Ocean Engineering Program, Faculty of Civil and Environmental Engineering, Institut Teknologi Bandung \\ ${ }^{2}$ Department of Oceanography, Faculty of Earth Science and Technology, Institut Teknologi Bandung \\ Jl. Ganesa No. 10, Bandung, Jawa Barat. \\ ${ }^{3}$ College of Science and Engineering, National University of Ireland Galway \\ University Road, H91 TK33 Galway, Ireland \\ ${ }^{4}$ Program of Disaster Management, Faculty of Societal Safety Sciences, Kansai University \\ 3-chōme-3-35 Yamatecho, Suita, Osaka 564-8680, Japan \\ Email: alamsyah@ocean.itb.ac.id
}

\begin{abstract}
The development planning of a tidally-influenced fluvial zone poses a complex interaction between river discharge and its effect on the tidal patterns, especially in the dense population and high economic activity like Palembang located in South Sumatra Indonesia. Previous studies on numerical modelling in this area have focused on the flood; however, the hydrodynamic modelling described interaction between river discharge and tidal is not described in more detail. The present study aims to better understand the zone by using a combination of numerical modelling and qualitative assessment of in situ measurement data. Hence, the water level condition in the study area is a mix of tidal and river discharge. A 2D-hydrodynamic modeling has been successfully conducted to assess their interaction in this zone properly by using the commercial software, called MIKE21 FM. This study describes setting up the computational model, boundary location, type of forcing (tidal and non-tidal), bedform roughness, turbulent viscosity and extensive calibration and validation. In situ measurement indicates that the site's water level and flow characteristic is complex, a mixture of tidal force from the downstream and river flows from the upstream in which seasons play an important role. It is found that comparing model outputs and the measurement data in the study area for the validation and verification process effectively describes the hydrodynamic condition in the fluvial-estuarine transition area of Palembang. As the model shows good reliability, the long term hydrodynamic in line with transport model should be developed to support the Palembang area rapid development.
\end{abstract}

Keywords: Tidally-influenced fluvial zone, in situ measurement, hydrodynamic modelling, season, Palembang

\section{Introduction}

Tidally-Influenced Fluvial Zone (TIFZ) is transitional between the river and tidal environments. This zone is an area where both river flow and tidal currents are significant, making it one of the most complex environments (Dyer, 1997; Hoitink and Jay, 2016; Matte et al., 2017a; 2017b). Palembang is one of the TIFZ in South Sumatra, Indonesia. It is located $72 \mathrm{~km}$ from the mouth of the Musi river, which is one of the largest and longest rivers in Indonesia. As commonly found in several locations, the influence of tidal in the river is decreasing towards upstream. However, it can be happened depending on the location's topography and geomorphology. Located in the eastern part of Sumatra, where the topographical conditions are a lowlands landscape, it allows tides to enter deep into the river. Since 1977, it was already known that there are differences in river water flow attributed to season or basin characteristics that significantly influence the tidal patterns (Hadi et al., 2018). In addition, based on field survey data and analysis of astronomical components at the study location, the sea-level changes in this location are still predominantly influenced by tides.

The zone has formed some of the areas with the highest population density. Shipping, aquaculture, and nature conservation are some of the interfaces that might be found (Greb and Martino, 2005). However, it also poses natural disasters such as a flood. Therefore, as the zone, Palembang, becomes strategically important to humans, the present study aims to better understand the zone, therefore maintainance, managing and conservation of the zone can be carried out properly.

Numerous studies have been conducted in this zone used various approaches of the numerical method (Zhang et al., 2015; Matte et al., 2017a; Sandbach et al., 2018). As for the study case, Palembang, the previous studies have conducted by Syarifudin (2017), Al Amin et al. (2017) and Farid et al. (2017) focusing on the floodplain simulation using 
an integrated 1D/2D model while the latter is completely 2D hydrodynamic modelling. Both of these models have used only tidal data sets to force the simulation, and therefore the TIFZ may not be adequately analysed.

The present study conducts a modelling study of the TIFZ, including different levels of process representation to evaluate the impacts of the computational domain, boundary location, forcing (tidal and non-tidal), bedform roughness and turbulent viscosity. The boundary condition on the river upstream side was using the river discharge, and on the downstream was using water elevation from the tidal analysis. Hence, the water level condition in the study area is a mix of tidal and river discharge. Furthermore, in a certain period, the numerical model of tidal currents, non-tidal currents (due to winds) is calibrated with in situ measurements in the field as quality control in modelling.

\section{Materials and Methods}

The hydrodynamic numerical model solves mathematical equations describing the water flow through a system conserving momentum (energy) and volume (mass). Hydrodynamic modelling has been developed and has become more advanced. For instance, MIKE $21 \mathrm{FM}$ is one of the cutting edge hydrodynamic modelling software packages. MIKE 21 FM solves the Navier-Stokes equations for an incompressible fluid within shallow water and the Boussinesq assumptions (DHI, 2012a; 2012b). It adopts an unstructured mesh comprising triangles or quadrilateral elements in the horizontal plane. This type of mesh has the advantage of capturing the details of water surface flow during the modelling process. In this study, the non-uniform mesh resolution was implemented in the model. The more detailed mesh has been implemented in the area of interest, while the coarser mesh was used in the outer part of the model domain. Hence, this allowed the computational duration to be more efficient.

The hydrodynamic model setup in this study is two-dimensional (2D), depth-averaged models. The model numerical solution for barotropic conditions is based on the depth-integrated incompressible Reynolds and the averaged Navier-Stokes equations. It consists of continuity, momentum, temperature, salinity and density equations. A Boussinesq assumption is applied in the model, which assumes that momentum transfer caused by turbulent is modelled with an eddy viscosity parameter.

\section{Domain}

This study simulates two interlinked models: a regional Musi river model and a detailed local model for the area of interest. The regional model simulation is to provide the tidal characteristics input for the local model boundary condition. This regional model extends from the river mouth to the upstream, where tidal influence is negligible based on its topographic elevation calculation. The regional model resolution is between 500-750 m of unstructured mesh (Figure 1). The Local model domain is within $5 \mathrm{~km}$ from the area of interest with a resolution between $10-20 \mathrm{~m}$ of unstructured mesh (Figure 2).

\section{Bathymetry}

The model land boundaries were obtained from the satellite image and DEMNAS \& BATNAS dataset from the Indonesian Geospatial Information Agency (BIG, 2000). The bathymetry information source is the open-source DEMNAS dataset provided by the Indonesian Geospatial Information Agency and detailed survey data in the area of interest (see Figure 2 ). From the bathymetric survey results, the area of interest is relatively shallow, especially on the edge of the river border, and the depth around the edge is less than $2 \mathrm{~m}$. While in the shipping channel area, the depth is maintained to a minimum of $12 \mathrm{~m}$.

\section{Boundary condition}

The water level and flow characteristic at the site is complex, a mixture of tidal force from the downstream and river flows from the upstream. Therefore, multiple configurations of input parameter type and location were tested to achieve the optimal boundary locations for the model (see the final boundary conditions in Figure 2.). The boundary conditions in final the Local Model use water level parameters and water flow velocity.

As shown in Figure 3, the water levels are predominantly tidal driven based on field survey data and analysis of astronomical components at the study location based on Egbert and Erofeeva (2002). While the boundary conditions on the river, for both upstream and downstream, are influenced by changes in water levels due to river discharge and tidal processes. Based on Nadal-romero et al., (2008), the river discharge for the model boundary was calculated based on rainfall intensity historical data from 2009 to 2018, the catchment area, and the surface type as can be seen in Figure 4. Both river discharge and rainfall intensity trends are consistent, where the rainy season between December and February has a greater magnitude than the dry season between June and September. The annual largest discharge on the river usually occurs in December, except in 2015 and 2018 (green line in Figure 4.). The input model uses the average debit data, representing the 10-year historical data (red line in Figure 4.). 


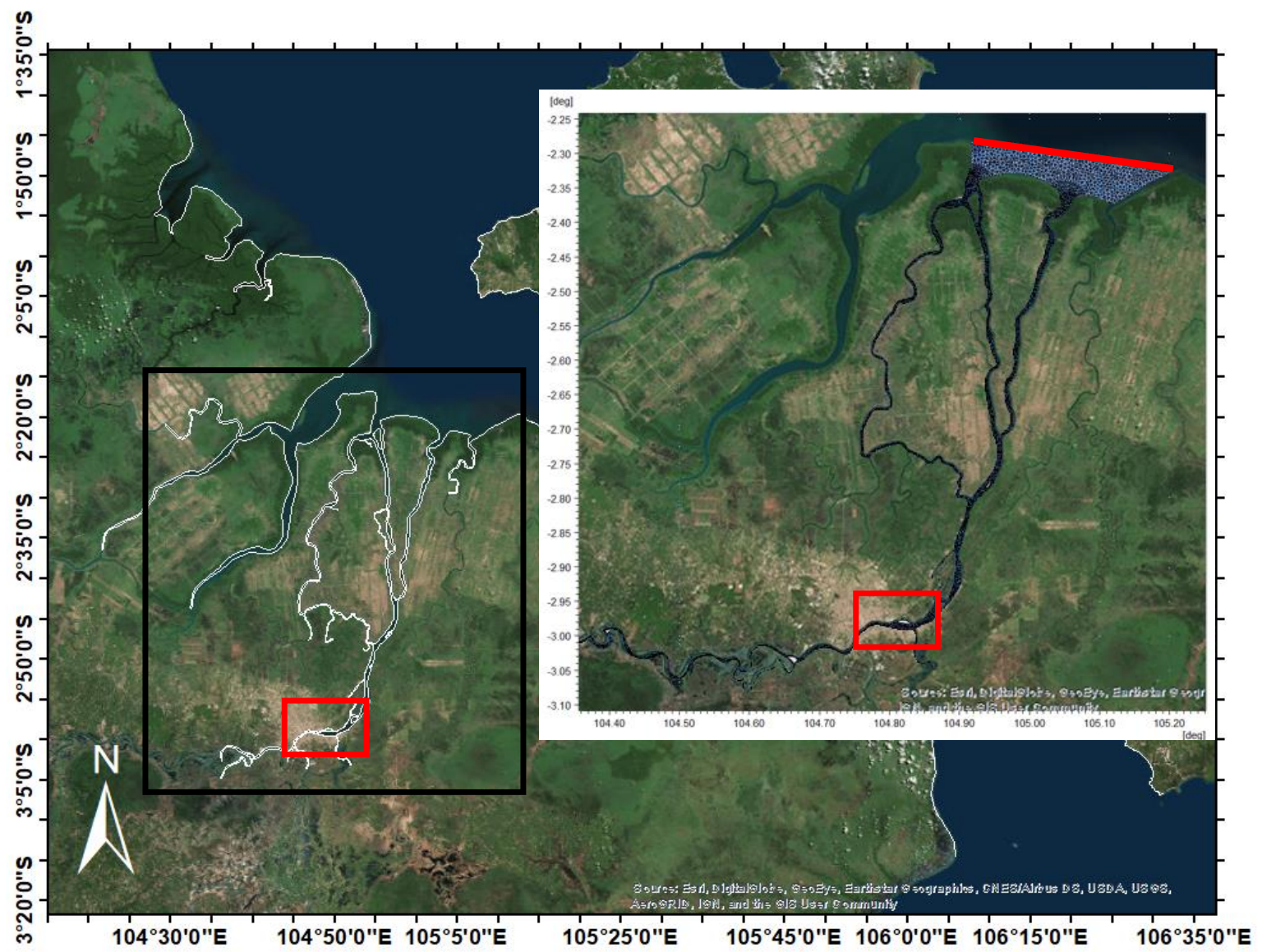

Figure 1.Map of study locations in Palembang, South Sumatra (red boxes). The inserted figure shows Global Domain with its open boundary location (red line).

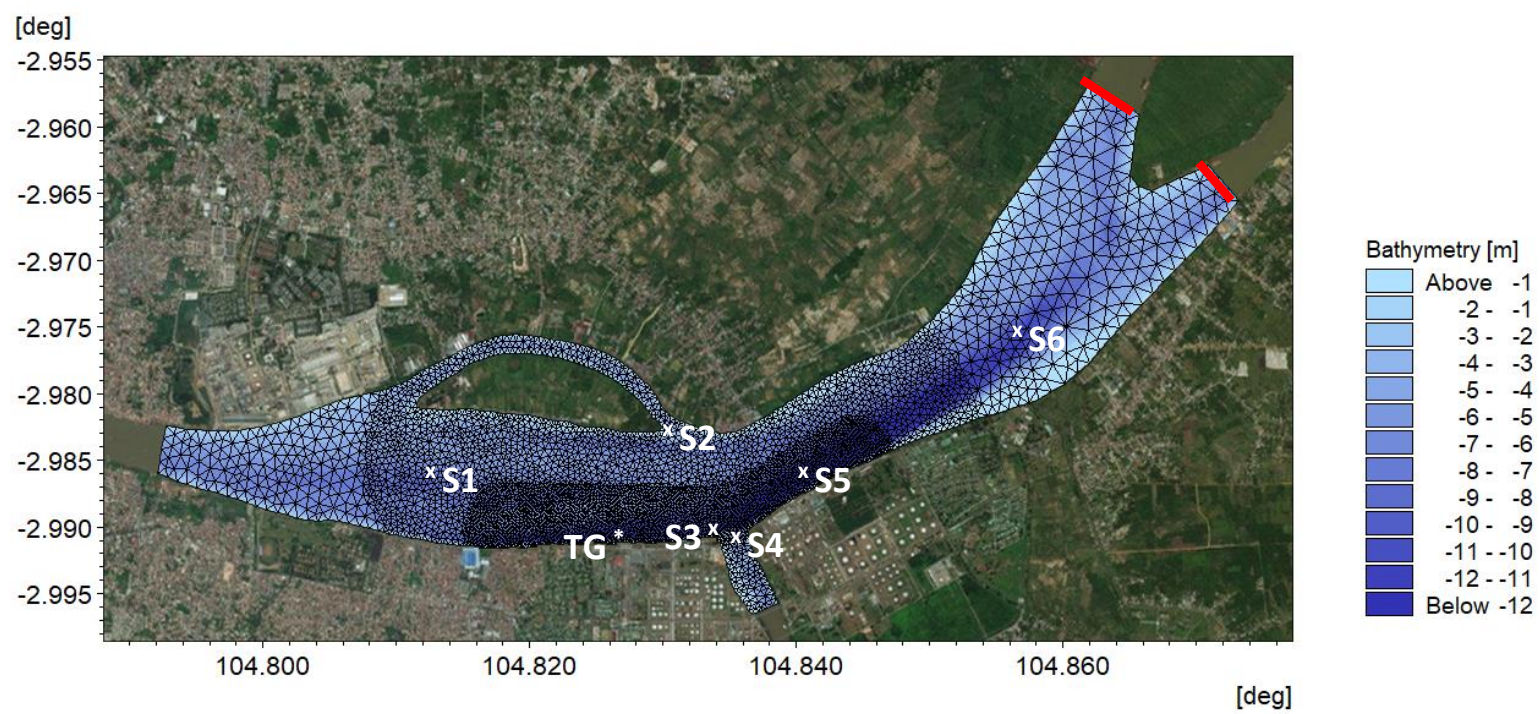

Figure 2. Local domain showing its mesh, bathymetry condition and observation location. Open boundaries lines in red (from Global Domain) and black (rivers discharges).

\section{Bed roughness}

The bed roughness parameter is adjusted during the model calibration process. It considers varying bed sediments, bedforms (ripples, sand waves, etc.) and vegetation (seagrass, mangroves, etc.). Since the bed condition in the study area is predominantly mud, the model using a higher 
manning number (lower resistance), as suggested by Soulsby and Wainwright (1987). In contrast, a Manning constant of 10 (higher resistance and impact on the flow) was implemented in the model for hard structures, such as jetty, found on several locations around the site. The final calibrated model uses a higher Manning constant value of 60 , gave a more accurate model simulation result and met the validation criteria. It is suitable for river-estuary systems with sloping topography and extensive watersheds commonly found on the east coast of Sumatra. This system generally has a smoother bottom surface, such as clay, with less bottom friction/resistance to the flow. The model setup physical and numerical parameters input are summarised in Table 1.

Table 1. Hydrodynamic Model Setup Summary.

\begin{tabular}{|c|c|c|}
\hline Parameter & \multicolumn{2}{|c|}{ Description } \\
\hline Software & \multicolumn{2}{|c|}{ D.H.I. Mike 21} \\
\hline & Modul & Flow Model HD-FM \\
\hline Simulation period & 1 Year covering the West and East Monsoons: & $\begin{array}{l}1 \text { January } 2018 \text { - } 1 \text { January } 2019 \\
\text { (By warming up three days 28-31 December 2018) }\end{array}$ \\
\hline Time-step & \multicolumn{2}{|c|}{600 seconds } \\
\hline Solution technique & Time & Low order, fast algorithm \\
\hline \multirow[t]{4}{*}{ (Shallow water equations) } & Space & Low order, fast algorithm \\
\hline & Minimum Time & $0.01 \mathrm{sec}$ \\
\hline & Maximum Time & $30 \mathrm{sec}$ \\
\hline & Critical CFL & 0.8 \\
\hline \multirow[t]{3}{*}{ Flood and dry } & Drying depth & $0.005 \mathrm{~m}$ \\
\hline & Flooding depth & $0.05 \mathrm{~m}$ \\
\hline & Wetting depth & $0.1 \mathrm{~m}$ \\
\hline Density & \multicolumn{2}{|c|}{ Barotropic } \\
\hline Eddy Viscosity & \multicolumn{2}{|c|}{ Smargorinsky formulation with a constant value of 0.28 (constant) } \\
\hline Bed resistance & \multicolumn{2}{|c|}{ Manning number that varies with domain (varying in the domain) } \\
\hline Wind forcing & \multirow{3}{*}{\multicolumn{2}{|c|}{$\begin{array}{c}\text { Wind speed and direction parameters are constant in the domain but vary with time } \\
\text { (Varying in time, constant in the domain) } \\
\text { Note: Wind data input is obtained from the EMCWF ERA-Interim reanalysis model } \\
\text { The flather condition parameters for all boundary conditions (water level, and current } \\
\text { velocity vector } \mathrm{U}, \mathrm{V} \text { ) that vary in time and along boundary conditions (Varying in time } \\
\text { and along the boundary) are obtained from prefix/preliminary model simulations and } \\
\text { river reliable discharge data }\end{array}$}} \\
\hline & & \\
\hline Boundary conditions & & \\
\hline
\end{tabular}

Water Level (MSL) [m]

Pure Tidal (MSL) [m]

Residual (MSL) [m]

ADMIRALTY

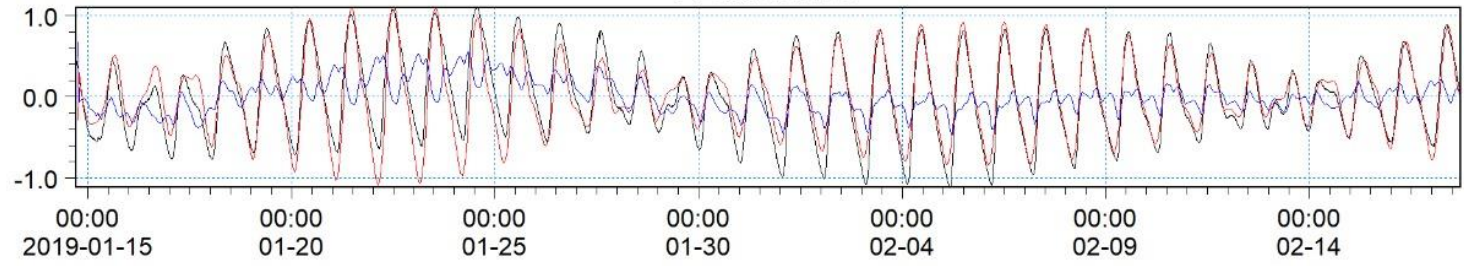

Water Level (MSL) [m]

$\begin{array}{ll}\text { Pure Tidal (MSL) } & {[\mathrm{m}]} \\ \text { Residual (MSL) } & {[\mathrm{m}]}\end{array}$

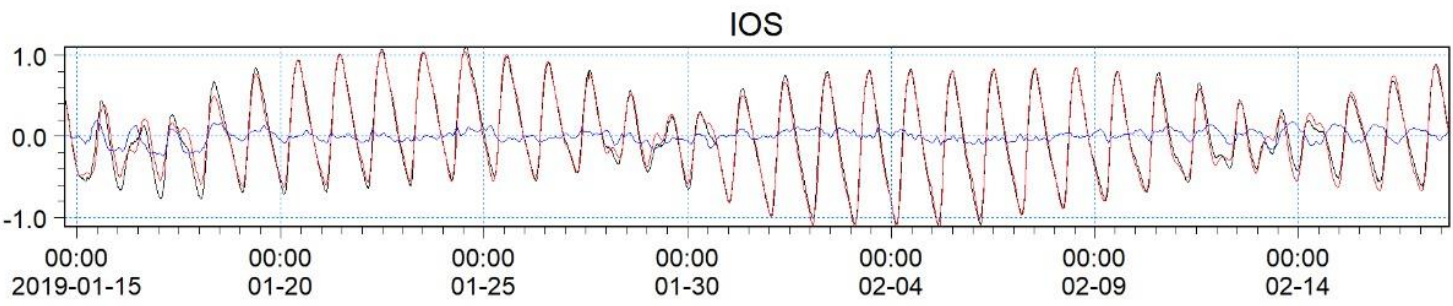

Figure 3. Tide and residual water level charts in Palembang. (top: based on Admiralty method, below: based on the IOS method) 


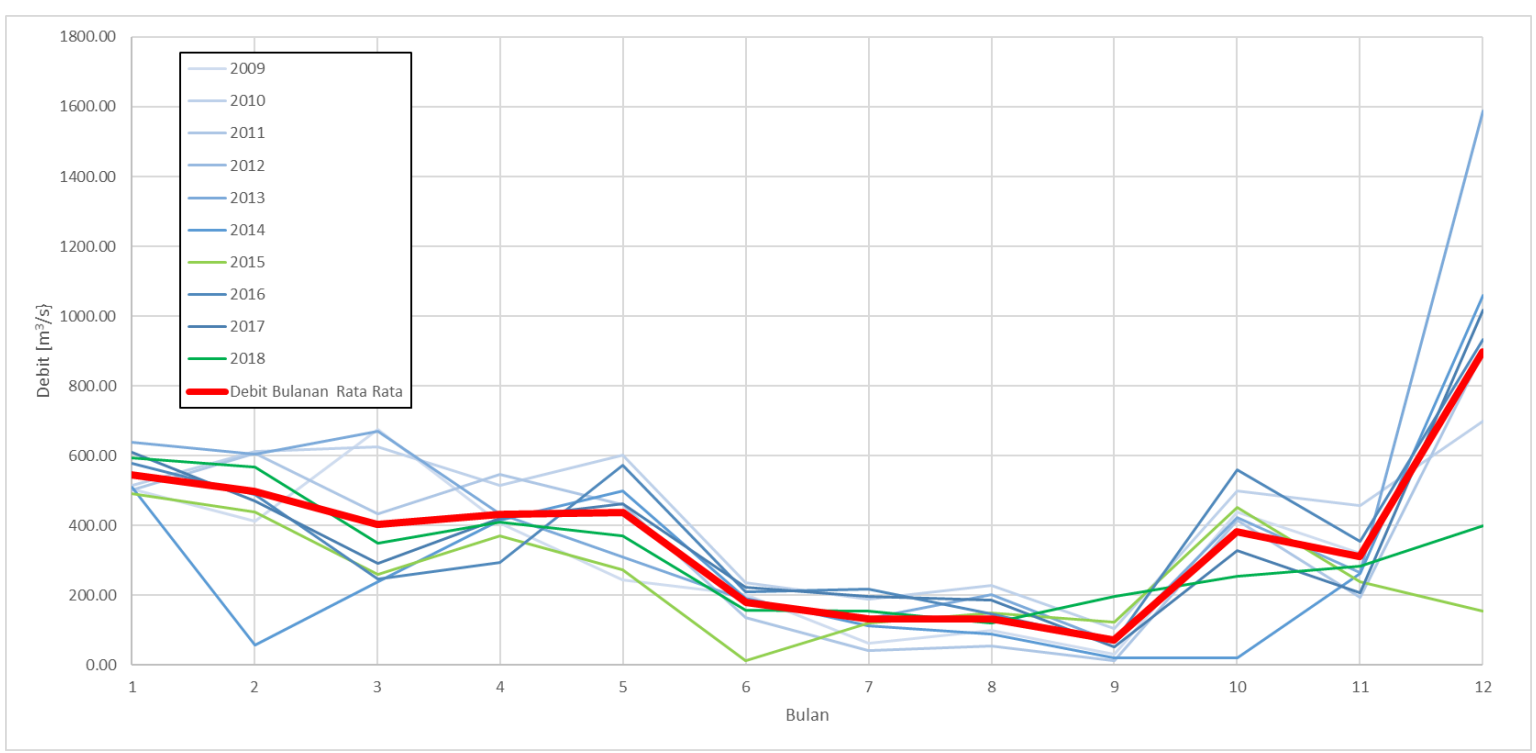

Figure 4. River discharge conditions are based on historical data between 2009-2018. The red line shows the average value, which is the value used in the model boundary state-input

\section{Result and Discussion}

\section{Model validation}

Following Foundation for Water Research (1998), model validation is carried out by qualitative measurement based on time-series comparison, and quantitative measurement by the root mean square error (RMSE) calculation. It is performed to measure the model reliability at 7 locations, as can be seen in Figure 2. There is 1 location for tidal elevation (i.e., $\mathrm{TG}$ ) which time-series comparison is shown in Figure 5. The RMSE value is $0.155 \mathrm{~m}$. In addition, the quantitative and qualitative measurements of the current speed and direction at 6 locations (i.e., S1 to S6) are presented in Table 2 and Figure 6, respectively. As can be seen, in general, the simulation results meet the criteria for maximum RMSE tolerance. For measurement locations S3 and S4, the quantitative validation approach is not feasible because most current speeds (above 90\%) are below $0.2 \mathrm{~m} . \mathrm{s}^{-1}$ as required. These findings show good model reliability.

\section{Model output}

The condition of the current pattern at the study location located at the river estuary is influenced by two factors, i.e. the tidal component from the sea's seaside and the river discharge component from the upstream side. The tidal type in the study location is diurnal, and the tidal range is approximately 2 meters. Meanwhile, river water's speed and discharge are influenced by rainfall, where the water discharge becomes more extensive in the rainy season and vice versa in the dry season.
The pattern of water flow in the Palembang study location during full moon tide conditions during the dry and rainy seasons in June and December are shown in Figure 7. Based on the simulation results, that the current velocity during the rainy season is more significant than during the dry season. This is due to the river discharge from upstream is greater during the rainy season than during the dry season.

The result also shows that the current velocity at low tide is higher than at the high tide as the tidal current goes in one direction with river discharge. The tidal current encounter the river discharge during the flood tide, then a stratification process occurs where the tidal current entering the estuary is on the inside or bottom while the river discharge leads to the mouthwatering upstream is at the water surface. The pattern for the bandages is similar to that of the full moon period. The difference lies in the magnitude of the current velocity, which is smaller than during the full moon due to the smaller tidal range.

Statistically, as shown in Figure 8, the maximum velocity at the site reaches $1 \mathrm{~m} . \mathrm{s}^{-1}$ at the river bend location. The average current velocity at the site ranges from $0.2-0.5 \mathrm{~m} . \mathrm{s}^{-1}$. According to Mason, (1981) the velocity of water currents can be grouped into very fast $\left(>1 \mathrm{~m} . \mathrm{s}^{-1}\right)$, fast $\left(0.5-1 \mathrm{~m} . \mathrm{s}^{-1}\right)$, medium (0.25-0.5 m.s. $\left.\mathrm{s}^{-1}\right)$, slow $\left(0.1-0.25 \mathrm{~m} . \mathrm{s}^{-1}\right)$ and very slow $\left(<0.01 \mathrm{~m} . \mathrm{s}^{-1}\right)$. In conclusion, the Palembang study location's average current speed category is moderate.

More detailed speed values at the review point can be seen in Figure 9. The river discharge factor can 
ILMU KELAUTAN: Indonesian Journal of Marine Sciences March 2022 Vol 27(1):83-92

Table 2. Current validation R.M.S.E. value between model and field measurement data.

\begin{tabular}{|c|c|c|c|c|c|}
\hline \multirow[b]{2}{*}{ Location (m) } & \multicolumn{3}{|c|}{ Flow Velocity } & \multicolumn{2}{|c|}{ Flow Direction } \\
\hline & $\begin{array}{l}\text { Maximum range } \\
\qquad\left(\mathrm{m}^{\mathrm{s}} \mathrm{s}^{-1}\right)\end{array}$ & $\begin{array}{l}\text { RMSE maximum } \\
\text { tolerance }\left(\mathrm{m} \mathrm{s}^{-1}\right)\end{array}$ & $\operatorname{RMSE}\left(\mathrm{m} \cdot \mathrm{s}^{-1}\right)$ & $\begin{array}{l}\text { Maximum } \\
\text { tolerance } \\
\text { (degrees) }\end{array}$ & $\begin{array}{l}\text { R.M.S.E. } \\
\text { (degrees) }\end{array}$ \\
\hline S1 & 0.26 & 0.10 & 0.08 & 20 & 19.90 \\
\hline S2 & 0.67 & 0.13 & 0.11 & 20 & 19.87 \\
\hline S3 & \multirow{2}{*}{\multicolumn{5}{|c|}{$\begin{array}{l}\text { Most of the velocity measurements at points S3 and S4 are below } 0.2 \mathrm{~m} . \mathrm{s}^{-1} \\
\text { (Tolerance applies to conditions of current velocity above } 0.2 \mathrm{~m} . \mathrm{s}^{-1} \text { ) }\end{array}$}} \\
\hline S4 & & & & & \\
\hline S5 & 0.60 & 0.12 & 0.12 & 20 & 6.75 \\
\hline s6 & 0.42 & 0.10 & 0.09 & 20 & 6.84 \\
\hline
\end{tabular}

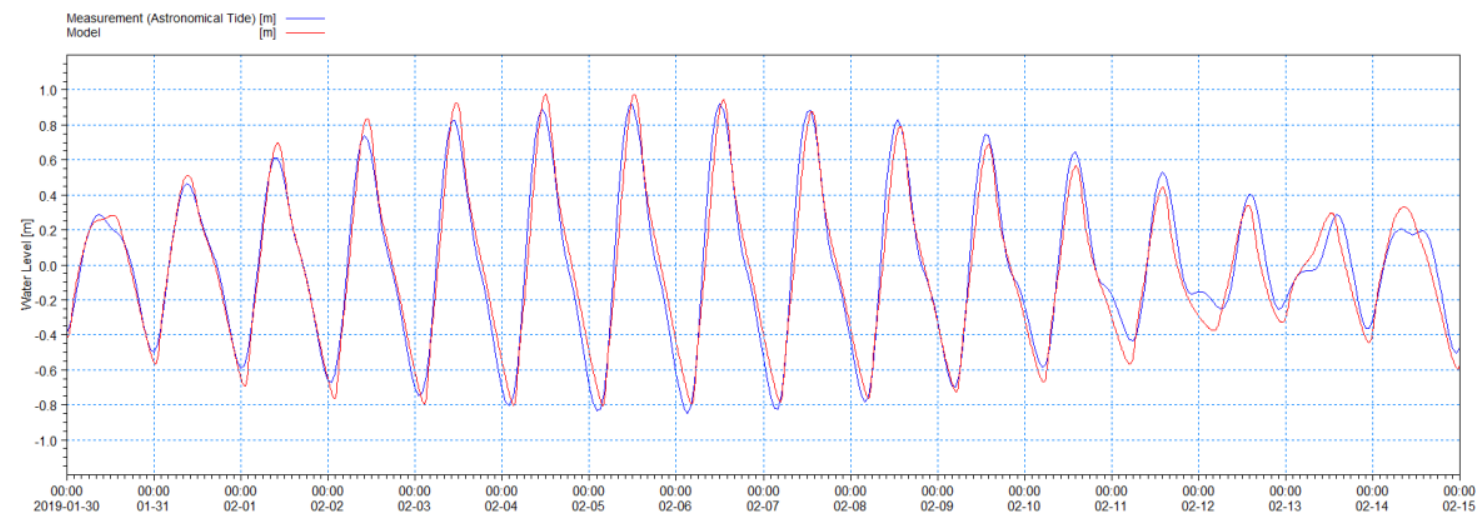

Figure 5. Tidal stream profile showing a) rising water during the neap cycle; b) falling water during the neap tide period; c) rising water during spring tide period, and d) falling water during the spring tide period
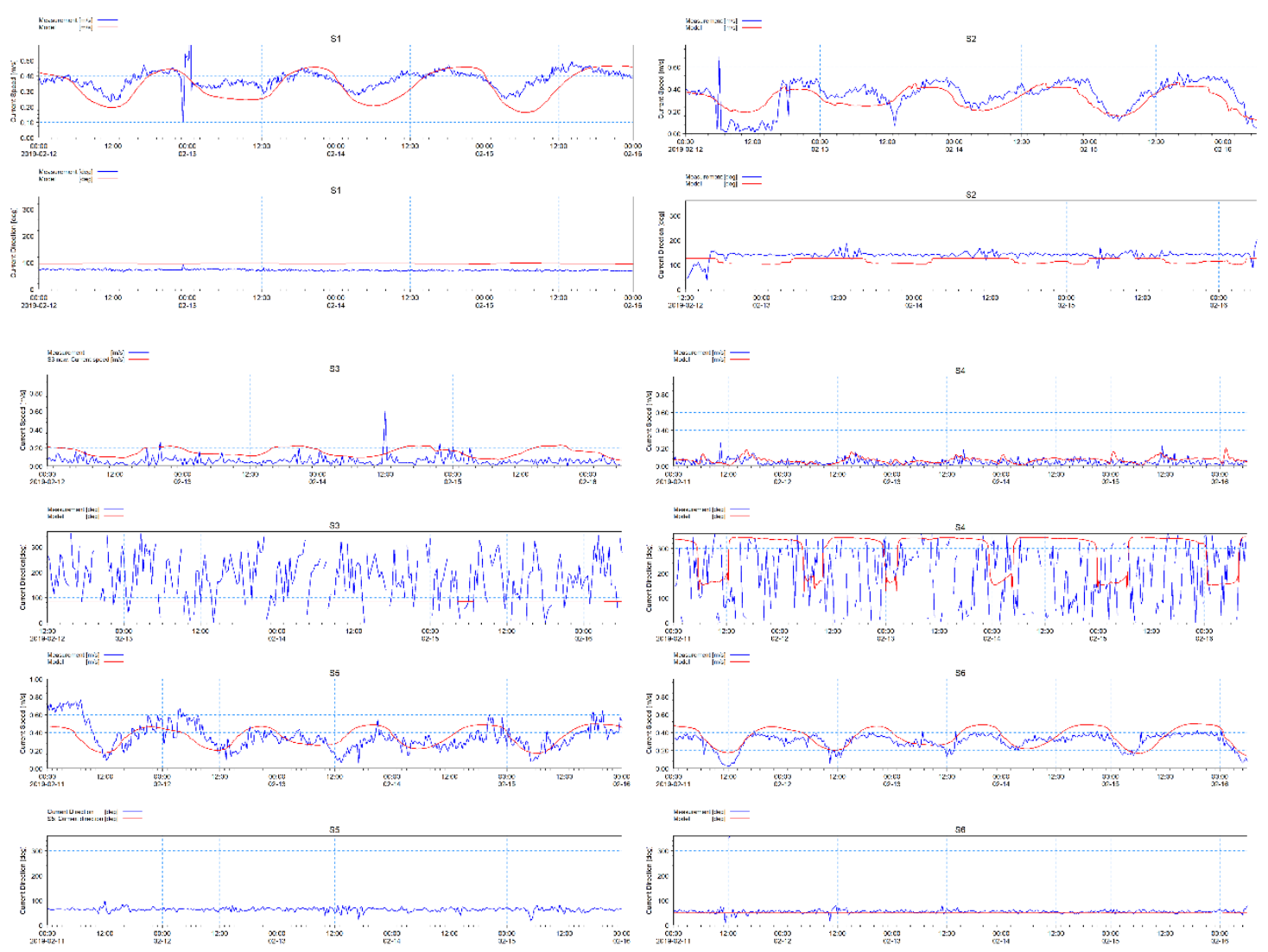

Figure 6. Model validation against A.W.A.C. measurement data at $\mathrm{S} 1$ to $\mathrm{S} 6$ location. 


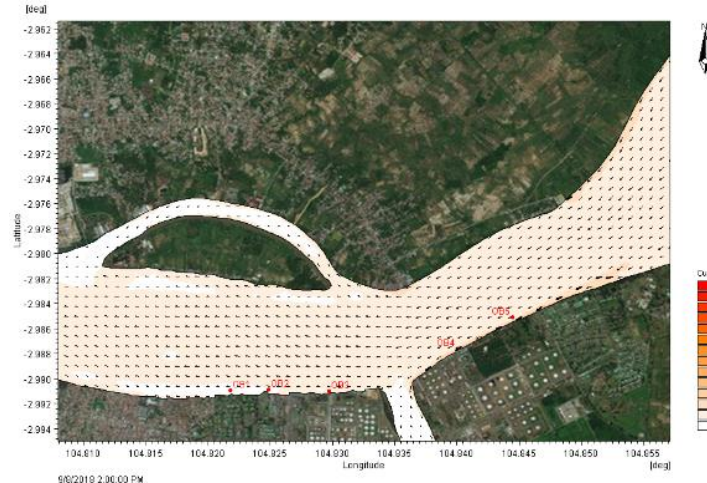

(a)

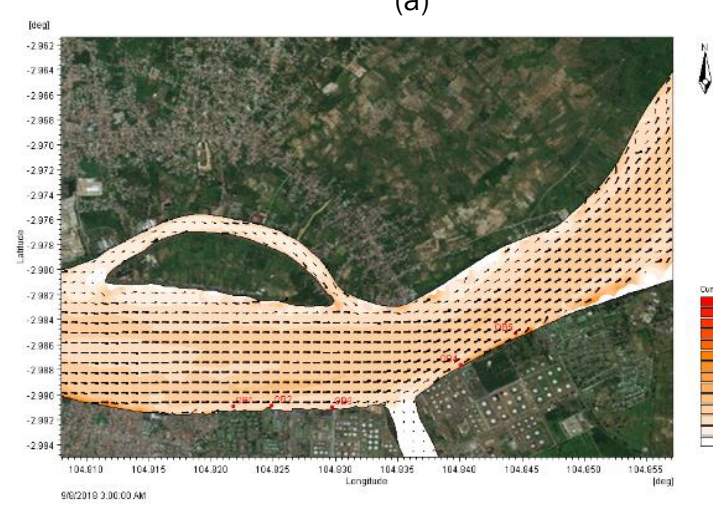

(c)

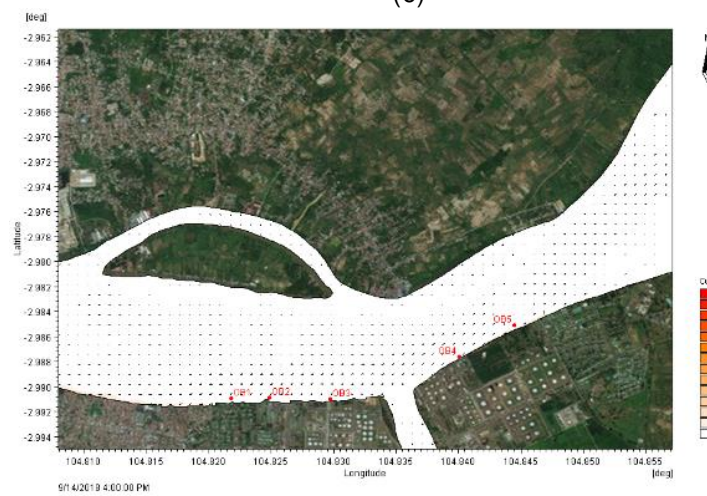

(e)

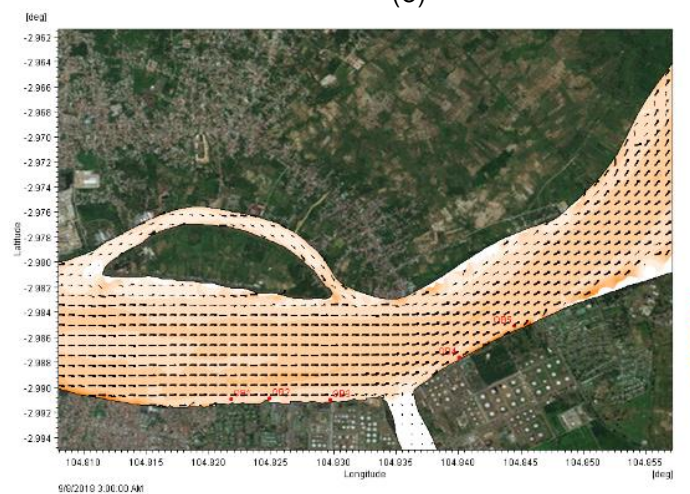

(g)

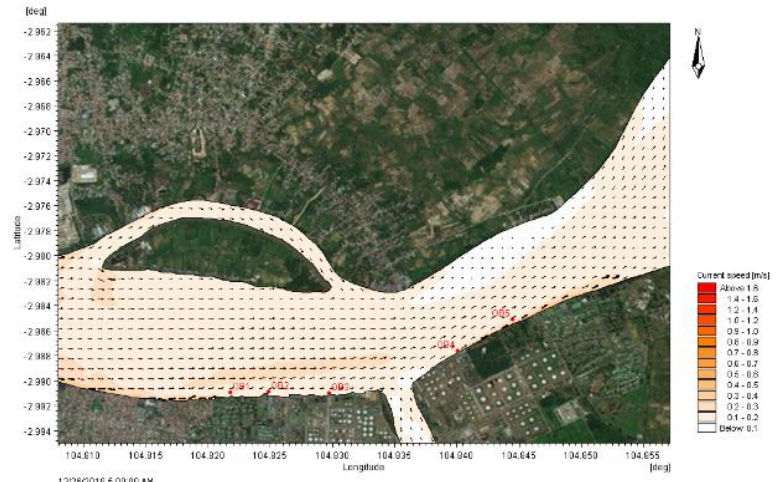

(b)

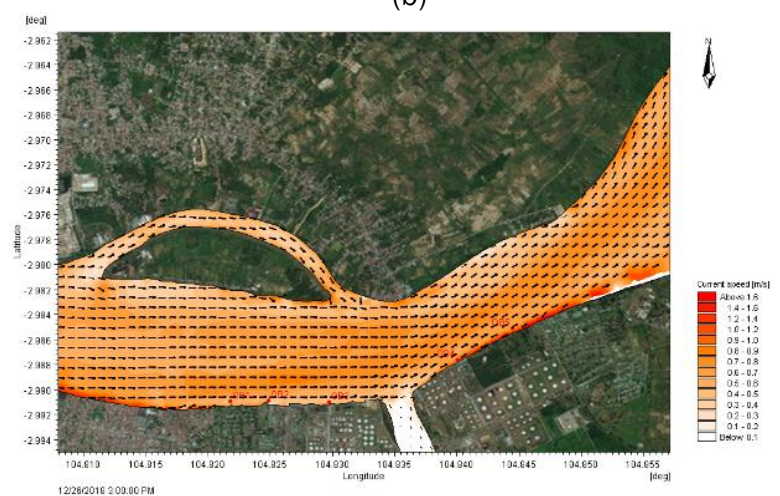

(d)

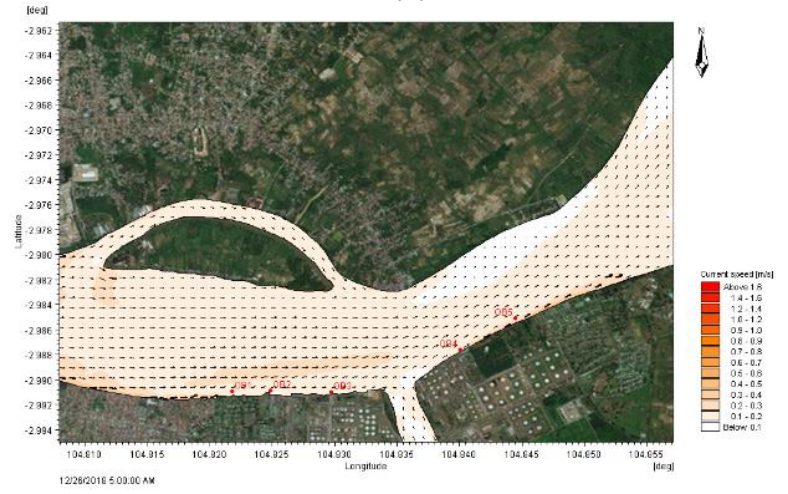

(f)

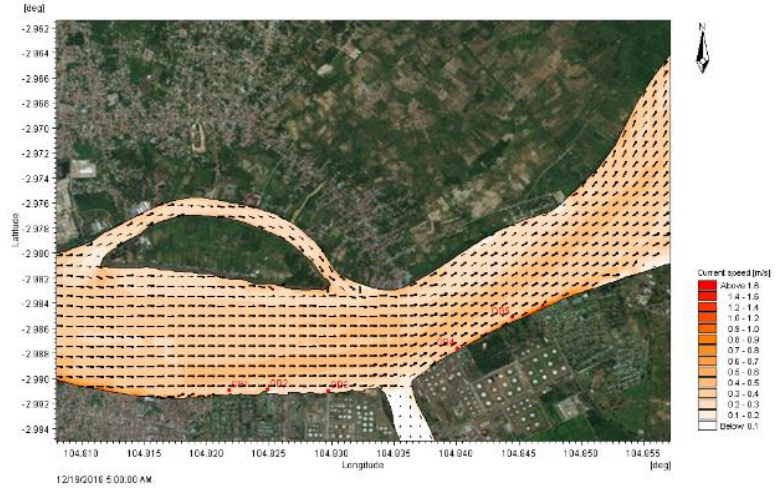

(h)

Figure 7. Spatial distribution of current velocity showing a) rising water during spring cycle on the dry season; b) rising water during spring cycle on the rainy season; c) falling water during spring cycle on the dry season; d) falling water during spring cycle on the rainy season; e) rising water during neap cycle on the dry season; f) rising water during neap cycle on the rainy season; g) falling water during neap cycle on the dry season; $h$ ) falling water during neap cycle on rainy season. 

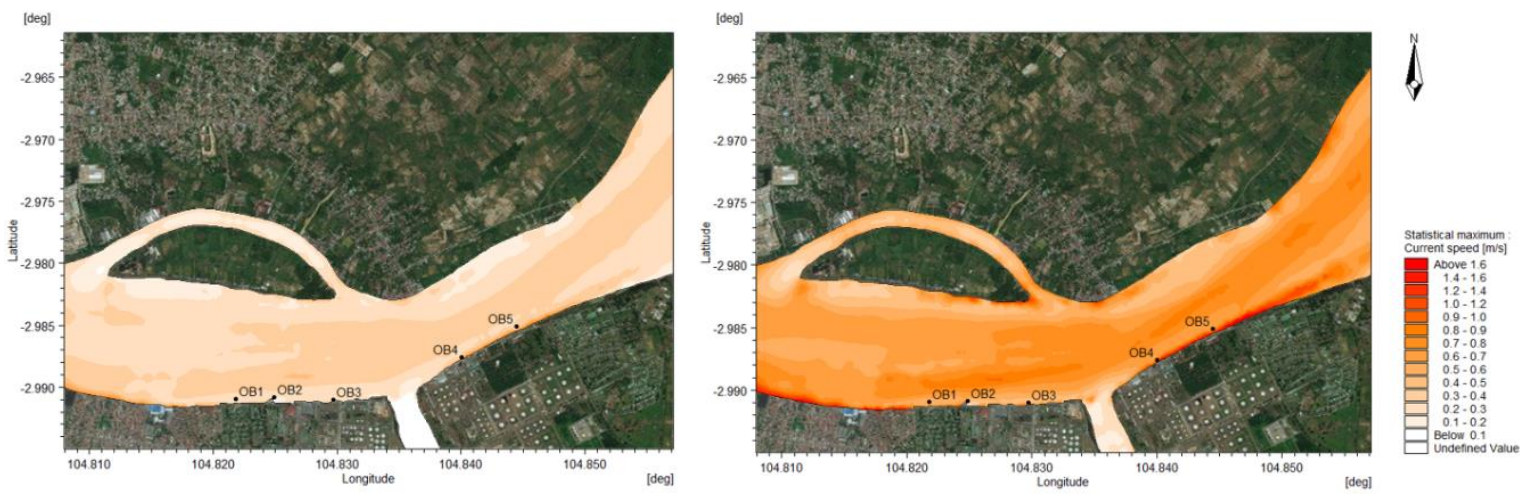

Figure 8. Spatial distribution of yearly current velocity showing average (left) and maximum (right)

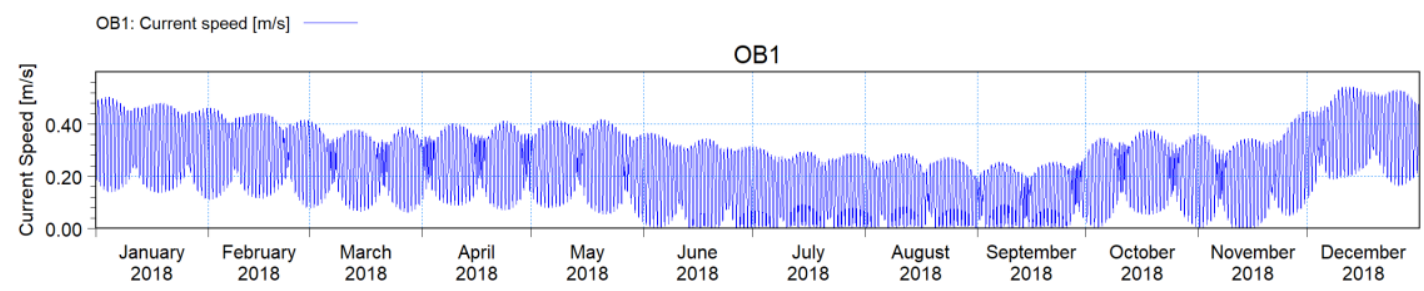

OB2: Current speed $[\mathrm{m} / \mathrm{s}]$

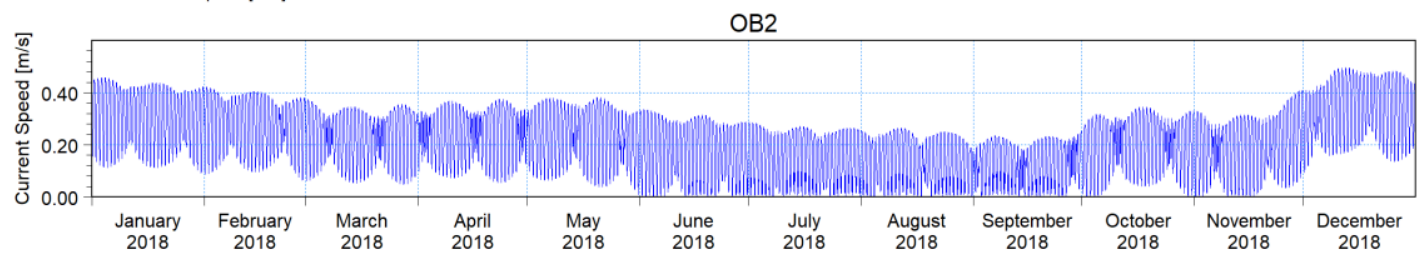

OB3: Current speed $[\mathrm{m} / \mathrm{s}]$

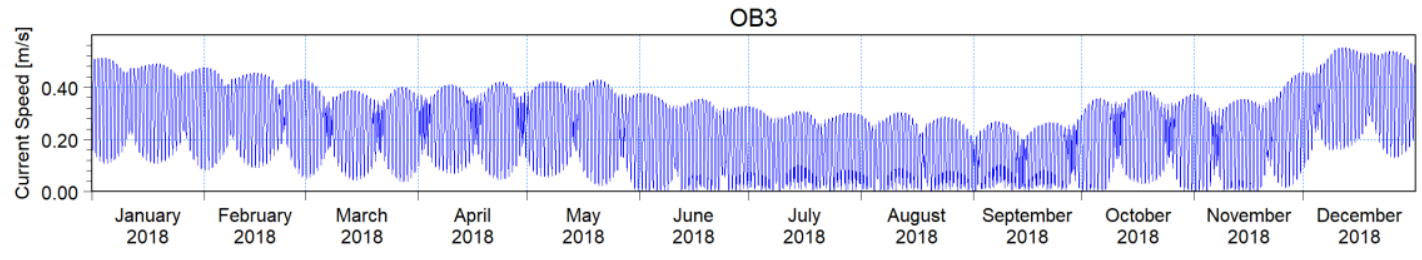

OB4: Current speed [m/s]

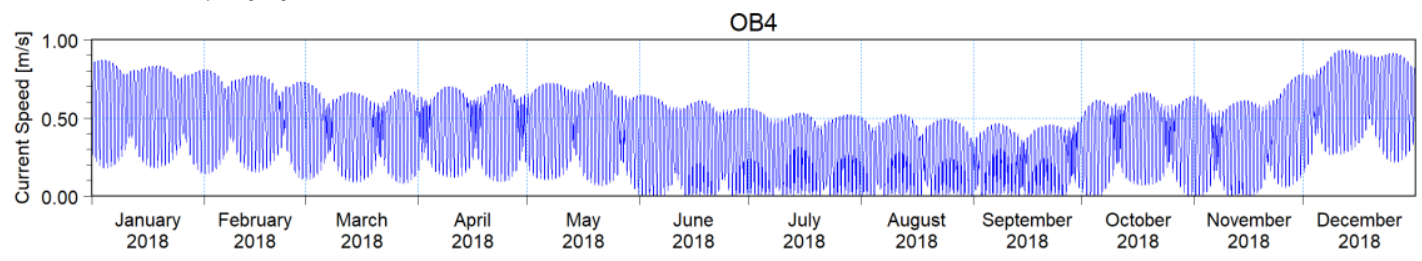

OB5: Current speed $[\mathrm{m} / \mathrm{s}]$

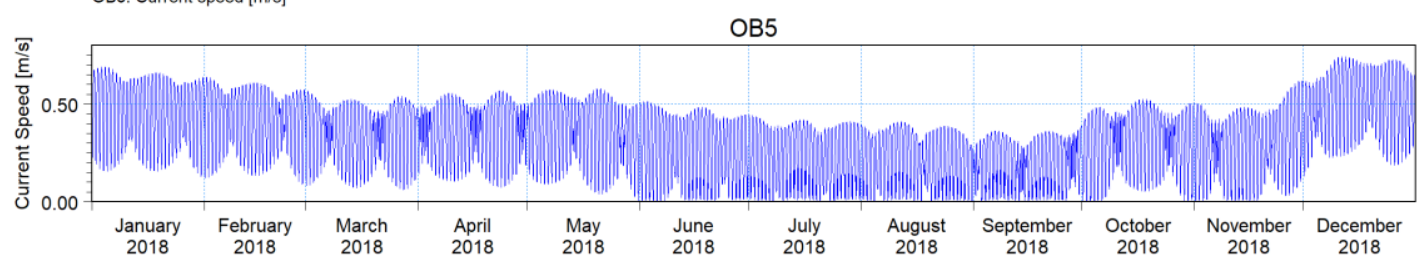

Figure 9. Timeseries of current speed at observation locations OB1 to OB5 


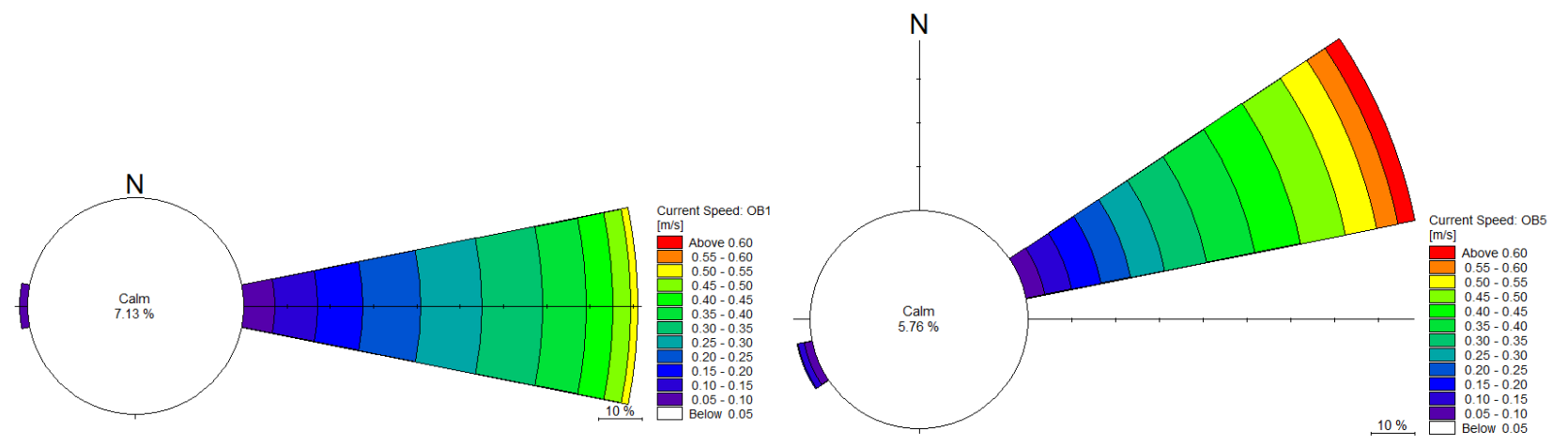

Figure 10. Current rose for OB1 (left) and OB5 (right).

influence the current velocity. In the rainy season between December and February, the flow velocity is generally more significant up to $0.2 \mathrm{~m} . \mathrm{s}^{-1}$ compare to the dry season between June and September. The model simulation results also show that the current speed is higher at the OB4 observation station compare to other stations. The OB4 station is located near the river bend, directly opposite the incoming flow from the upstream in the middle of the river cross-section, which has a flow velocity more remarkable than the river bank.

From the current rose of model results, as shown in Figure 10, it is found that both at low tide and tide, the direction of the flow always leads outward (towards the downstream or estuary). Similar phenomena are also found on the in situ measurement data carried out during the rainy season, and it confirms the effect of the discharge from the river is substantial.

\section{Conclusion}

The results in this paper illustrate that the hydrodynamic condition in the fluvial-estuarine transition area of Palembang can be effectively analysed by using a combination of numerical modelling (MIKE 21 FM) and qualitative assessment of in situ measurement data. The current conditions in the study area are influenced by tidal from the sea and river water discharge from the upstream. The tidal type is diurnal, with a tidal range approaching 2 $\mathrm{m}$. Current speed at rainy season is more significant than during the dry season due to the upstream river discharge factor. The study reveals a vertical stratification of water currents where the tidal currents entering the estuary is moving on the bottom. In contrast, the river discharge moving towards the downstream is on the surface of the waterbody. In addition, as future work, sediment transport analysis is deemed important as the river upstream significantly affect the study area.

\section{Acknowledgement}

The authors gratefully acknowledge the support and contributions of the Ocean Engineering Program and Department of Oceanography, Institut Teknologi Bandung and PT. Mahakarya Geo Survey for software license.

\section{References}

Al Amin, M.B., Sarino \& Haki, H. 2017. Floodplain simulation for Musi River using integrated 1D/2D hydrodynamic model. MATEC Web Conf. 101:05023. https://doi.org/10.1051/matecco nf/201710105023.

Badan Informasi Geospasial [BIG]. 2020. Real time tidal observation. http://tides.big.go.id:8888/ dash/

Danish Hydraulic Institute [DHI]. 2012a. MIKE 21 Flow Model FM, Hydrodynamic Module Scientific Documentation. DHI. 58p.

Danish Hydraulic Institute [DHI]. 2012b. MIKE 21 Spectral Wave FM Spectral Wave Module, Scientific Documentation. DHI. 66p.

Dyer, K.R. 1997. Estuaries: a Physical Introduction, second ed. John Wiley and Sons, Chichester, UK. 210p.

Egbert, G.D. \& Erofeeva, S.Y. 2002. Efficient inverse modeling of barotropic ocean tides. Journal of Atmospheric and Oceanic Technology, 19(2): 183-204. https://doi.org/10.1175/1520-0426 (2002)019<0183:EIMOBO>2.0.CO;2

Farid M., Marlina A. \& Kusuma M.S.B. 2017 Flood hazard mapping of Palembang City by using 2D model. AIP Conference Proceedings, 1903 (1): 100009. https://doi.org/10.1063/1.5011619 
Foundation for Water Research. 1998. A Framework for Marine and Estuarine Model Specification in the UK (FR-0374)

Greb, S.F. \& Martino, R.L. 2005. Fluvial-estuarine transitions in fluvial-dominated successions: examples from the Lower Pennsylvanian of the Central Appalachian Basin. Spec. Publs int. Ass. Sediment., 35: 425-451. https://doi.org/10. 1002/9781444304350.ch23.

Hadi, S., Hanson, A.J., Koesoebiono, Mahlan, M., Purba, M. \& Rahardjo, S. 2018. Tidal Patterns and Resource Use in the Musi-Banyuasin Coastal Zone of Sumatra. Marine Research in Indonesia, 19: 109-135. https://doi.org/10. 14203/mri.v19i0.376

Hoitink, A.J.F. \& Jay, D.A. 2016. Tidal river dynamics: Implications for deltas. Rev. Geophys., 54(1): 240-272. https://doi.org/10.1002/2015RG0 00507

Mason, I. 1981. Algebraic reconstruction of a twodimensional inhomogeneity in the High Hazles seam of Thorseby colliery. Geophysics, 46: 298308. https://doi.org/10.1190/1.1441200

Matte, P., Secretan, Y. \& Morin, J. 2017a. Hydrodynamic Modeling of the St. Lawrence Fluvial Estuary. I: Model Setup, Calibration, and Validation. J. Waterway, Port, Coastal, Ocean Eng., 143(5): 04017010. https://doi.org/10. 1061/(ASCE)WW.1943-5460.0000397

Matte, P; Secretan, Y. \& Morin, J. 2017b. Hydrodynamic Modeling of the St. Lawrence
Fluvial Estuary. II: Reproduction of Spatial and Temporal Patterns. J. Waterway, Port, Coastal, Ocean Eng., 143(5): 04017011. https://doi. org/10.1061/(ASCE)WW.1943-5460.0000394

Nadal-Romero, E., Regues. D. \& Latron, J. 2008. Relationship among rainfall, runoff, and suspended sediment in a small cathment with Badlands. Catena, 74(2), 127-136. https://doi. org/10.1016/j.catena.2008.03.014.

Sandbach, S.D., Nicholas, A.P., Ashworth, P.J., Best, J.L., Keevil, C.E., Parsons, D.R., Prokocki, E.W. \& Simpson, C.J. 2018. Hydrodynamic modelling of tidal-fluvial flows in a large river estuary. Estuar. Coast. Shelf. Sci., 212: 176-188. https://doi.org/ 10.1016/j.ecss.2018.06.023

Soulsby, R. \& Wainwright, B.L.S.A. 1987. A criterion for the effect of suspended sediment on nearbottom velocity profiles. J. Hydraul. Res., 25: 341-356. https://doi.org/10.1080/00221688 709499275

Syarifudin, A. 2017. The influence of Musi river sedimentation to the aquatic environment. MATEC Web of Conferences 101: 04026. https://doi.org/10.1051/matecconf/2017101 04026

Zhang, M., Townend, I.H., Cai, H. \& Zhou, Y. 2015. Seasonal variation of tidal prismand energy in the Changjiang River estuary: A numerical study. Chin. J. Oceanol. Limnol., 34: 219-230. https://doi.org/10.1007/s00343-015-4302-8 